\title{
BREDEKAMP, H. (2015). TEORIA DO ACTO ICÓNICO. LISBOA: KKYM
}

\author{
Isabel Macedo
}

Historiador de arte, Horst Bredekamp (Kiel, 1947) é professor na Universidade Humboldt, membro permanente do Instituto de Estudos Avançados de Berlim e presidente do Laboratório Interdisciplinar, Imagem, Conhecimento e Forma. Desde 2000 orienta um núcleo multidisciplinar que trabalha sobre a imagem técnica no campo das ciências, das tecnologias e no domínio da medicina. O tema da mediação das imagens tem estado no centro da sua atividade desde a sua tese de doutoramento Kunst als Medium sozialer Konflikte [A arte como meio do conflito social] (1975), e continua a informar a sua atividade enquanto historiador de arte. É coeditor de diversos estudos sobre a teoria e a história das imagens, destacando-se a codirecção da edição crítica da obra completa de Aby Warburg. A obra Teoria do acto icónico (2015), que apresentamos nesta recensão, envolve um vasto período temporal, desde a Pré-história até aos nossos dias e centra-se em objetos muito precisos, com consequências vastas para a compreensão do papel da arte na história, na sociedade e nas ciências'. Entre os trabalhos mais marcantes de Horst Bredekamp assinalamos: Antikensehnsucht und maschinenglauben [A nostalgia do antigo e o culto da máquina] (1993); Thomas Hobbes visuelle strategien, Der Leviathan [Estratégias visuais de Thomas Hobbes, O Leviatã] (1999); Darwins Korallen [Os corais de Darwin] (2005) e Le déclin du platonisme [O declínio do neo-platonismo] $(2005)^{2}$. O autor combina a perspetiva historicista, a análise de fontes documentais, a análise dos processos de transformação das imagens ao longo do tempo, com contribuições teóricas de vários campos científicos. A reflexão interdisciplinar desenvolvida por Bredekamp, durante décadas, culminou na obra Teoria do acto icónico (2015), onde se ensaia uma "fenomenologia da imagem ativa" (p. 13), ou da imagem como ato.

A quantidade de imagens com as quais somos confrontados na contemporaneidade e os usos que se faz destas têm gerado inúmeros estudos e reflexões que se intensificaram nas últimas décadas. Pela comunicação social, na vida política, em conflitos, nas ciências ou na área do direito, as imagens são hoje "experienciadas e tratadas como elementos bem no centro da vida social" (p. 9). De facto, o autor, começa a sua reflexão por assinalar o papel das imagens, por exemplo, no quotidiano político, referindo que estas "podem ser aliadas ou traidoras do poder político" (p. 8) e que, através dos meios de comunicação e da internet, têm a potencialidade de guiar conflitos armados "ou até mesmo tomar o seu lugar" (p. 8). Para o autor, o mundo atual só poderá ser verdadeiramente entendido se considerarmos o elemento icónico.

\footnotetext{
' YMAGO, retirado de http://cargocollective.com/ymago/bredekamp-tutti ${ }^{2}$ YMAGO, retirado de http://cargocollective.com/ymago/bredekamp-tutti
} 
Um comentário de Leonardo da Vinci dá mote à obra de Horst Bredekamp. Para o autor, a frase "Não me descubras, se a liberdade te é cara, porque a minha face é cárcere do amor" (p. 9), expõe o problema da autonomia da imagem. Na sua opinião, a imagem depois de criada "torna-se independente e objeto de admiração reverente, mas também de medo, como a mais forte das sensações" (p. 11). No entanto, desde o Iluminismo a ideia de imagens vivas foi relegada para objeto de estudo da antropologia e da etnologia. A discussão em torno da inorganicidade e da vida própria da imagem tem gerado várias controvérsias. Warburg já reconhecia a vitalidade das imagens, a sua capacidade de ferir, aquilo que o autor designa de "fenomenologia da imagem activa" (p. 13), ou "enárgeia". Perante imagens vivas, e segundo Da Vinci, o observador pode "abdicar da contemplação da obra de arte ou perder a sua liberdade" (p. 13). Para entender este conceito de ato icónico, o autor traça um paralelo com o conceito de ato de linguagem, desenvolvido por Searle e Austin ${ }^{3}$.

Depois de uma longa introdução em que esclarece os conceitos em análise, o autor apresenta uma tipologia do ato icónico. Esta clarificação concetual foi acompanhada por uma demonstração, usando várias imagens provenientes de diferentes áreas geográficas, mas também de períodos temporais distintos. $O$ autor refere, por exemplo, um conjunto de conchas perfuradas com cerca de 75.000 anos que, supostamente, terão sido parte de um adorno, constituindo um exemplo da potencialidade do homem na transformação de materiais naturais em imagens, atribuindo-lhes uma esfera própria, associada a uma prática comum e partilhada. Nesse período, as imagens não constituíam um acrescento estético, mas o "fomento das culturas primordiais" (p. 19), reforçando a ideia da imagem como "determinação essencial da espécie humana" (p. 19). Numa primeira aceção, o conceito de imagem abarca toda e qualquer forma modelada, não se estabelecendo uma separação entre imagem e arte. Bredekamp mobiliza o entendimento de imagem (simulacrum) de Alberti, que concebe como imagem as formas modeladas em que se verifica "um mínimo de manipulação humana" (p. 21).

O autor procura especificar os seus conceitos com a ajuda de Platão, Heidegger e Lacan. Na sua perspetiva, Platão era contrário às imagens que ele via como ameaça à comunidade, ao passo que acolhia e defendia as imagens que reconhecia como fator de civilização. Entre ambos os extremos encontra-se uma angústia profundamente enraizada, segundo Bredekamp, a de se deparar na imagem com uma esfera que escapa ao controlo filosófico (p. 26). Heidegger e Lacan foram também dominados pela angústia de Platão a propósito dos efeitos das imagens, tendo Lacan, na confrontação com a "imagem indomável" (p. 31), mobilizado o olhar para o mundo dos artefactos não artísticos.

Apesar das várias tentativas que procuraram aplicar teorias do ato linguístico à imagem, o autor considera que ao contrário do ato linguístico, "a problemática do acto icónico consiste em individuar a força que permite à imagem, na contemplação ou no toque, saltar de um estado de latência, para a eficácia externa no âmbito do sentir, do pensar e do agir" (p. 34). Neste sentido, o autor concebe o ato icónico como tendo um

\footnotetext{
${ }^{3}$ Ver Speech-act de J. R. Searle (1969) e How to do things with words de J. L. Austin (1962).
} 
efeito "no plano do sentir, do pensamento e da acção, que dimana da força da imagem e da interacção com quem a olha, toca e também escuta" (p. 34).

Bredekamp mostra que as primeiras estátuas gregas "falam" na primeira pessoa para "enunciar" o seu dono ou o seu autor. Cada objeto carrega de algum modo esse discurso. Esta tradição continua em algumas das assinaturas de obras na Idade Média, nas pinturas renascentistas (nomeadamente as de Jan Van Eyck), na propriedade de certas armas, estátuas como o Pasquino de Roma e, finalmente, no trabalho de Nikki de Saint Phalle, Tu est Moi, onde a artista justapõe objetos com conotação violenta, como armas e martelos, em suportes de gesso e madeira. Este tipo de manifestação, de obras que falam na "forma-eu", "atestam e confirmam a impressão, que emerge claramente em todas as épocas e em cada cultura, de que os artefactos, embora feitos com um intuito artístico, possuem vida própria" (p. 68), sendo esta constatação "estranha e perturbadora" (p. 68). Para o autor, obras como esta, que 'falam na forma-eu', lançam os fundamentos para a teoria do ato icónico.

Horst Bredekamp propõe uma tipologia do ato icónico: esquemático, substitutivo e intrínseco. A primeira forma identificada é o ato icónico esquemático onde todas as imitações da forma aparente de vida são agrupadas: o modelo é um exemplo paradigmático, na sua articulação produz a ilusão da vida. É o corpo humano que é principalmente esquematizado para dar essa impressão. Assim, a imagem viva, as pinturas baseadas em pinturas ao vivo e, mais recentemente, as performances de Gilbert e Georges e as fotografias de Cindy Sherman, são manifestações do ato icónico esquemático. Essas obras jogam com o sentimento de empatia, mas também com a distância. $\mathrm{Na}$ verdade "foi-lhes infundido um movimento interno, porque se fixam e imobilizam; por fim, graças a uma intervenção artificial, foram emocionalmente animadas, porque em si mesmas eram privadas de sentimento" (p. 122). A segunda modalidade do ato icónico esquemático é o autómato. As figuras simulam esquemas, impressionando o observador através "da sua vitalidade autónoma" (p. 102). Em síntese, o ato icónico esquemático da imagem reside em tornar a imagem viva ao assimilar corpo e vida, anulando assim a distância entre inanimado e animação.

A segunda categoria desenvolvida pelo autor é o ato icónico substitutivo, em que os corpos são tratados como imagens e as imagens como os corpos. Vera icon (verdadeira imagem) manifesta esta substituição, "o corpo está plenamente presente, apesar de já não ser constituído por matéria viva” (p. 134). Pela impressão do corpo em imagem certifica-se a autenticidade e a atividade intrínseca do artefacto. No entanto, a substituição das pessoas pela imagem possibilita também o iconoclasmo, e "a interpretação dos corpos como imagens pode, em última análise, significar que os seres humanos sejam tratados de forma iconoclasta" (p. 172). Deste modo, para além de considerar o poder perturbador da imagem, o autor também aborda o seu poder destrutivo. A 'guerra das imagens', referida por Bredekamp, remete-nos para o facto de, ao longo da história, terem sido usados corpos de soldados e funcionários inimigos mostrando-os "não como imagem porque tinham sido mortos, mas para os matar em vista da sua utilização como imagem" (p. 170). Os média têm aqui um papel central. Crimes e torturas são cometidos 
e contemplados, através de internet, esbatendo-se a distância entre ação, imagem e observação. É, assim, necessário reconhecer e combater o ato icónico substitutivo na sua vertente destrutiva. Horst Bredekamp argumenta que ao observar os conflitos ao longo das últimas décadas em torno das imagens, "nenhuma educação sobre a imagem estará à altura dos desafios atuais se o dever da distância, negligenciado em várias esferas da vida, não tiver recuperado a sua importância" (2016, s.p.). Com o ato de substituição, que diz respeito à troca de corpos e imagens, a fronteira entre os corpos e as imagens torna-se uma questão de vida e de morte. Após o ataque de Charlie Hebdo, ficou claro para o autor que o ato icónico não é um jogo de espírito, mas uma realidade amarga (Bredekamp, 2016).

A terceira categoria, o acto icónico intrínseco, produz os seus efeitos a partir da "irresistibilidade da forma enquanto forma" (p. 256). O olhar da imagem, a agilidade da sua forma, a sua dinâmica expressiva são alguns dos fatores que conferem força ativa à imagem. Na parte final do livro, o autor analisa o ato icónico tendo por base uma antropologia filosófica que vem de Warburg, mas também de Cassirer e de Adorno. Segundo ele, o homem é um animal simbólico, pois a atividade corporal e a concetualização são inseparáveis. É no corpo, em última análise, que reside o poder criativo. $O$ ato icónico abrange assim as "esferas da vida, da permuta e da forma; abarca o esquema, a substituição e a acção intrínseca da forma liberta de qualquer finalidade" (p. 252). O autor termina afirmando que as imagens não constituem um desvio da realidade, mas uma das suas condições.

Sendo sobejamente reconhecida a forma como o autor traz para o campo da história da arte a maré contemporânea das imagens, olhando o mundo como imagem, vozes críticas, como Gunthert (2016), consideram que o autor da obra mobiliza exemplos principalmente do campo da arte, negligenciando formas artísticas como a gravura ou a fotografia, ou os usos comuns da imagem. Segundo este autor, Bredekamp não acompanha os avanços propostos pelo historiador de arte Ernst Gombrich (1996), atento ao graffiti, à banda desenhada ou aos média. Faltam, ainda, estudos que remetam para os efeitos positivos de formas visuais, como a publicidade. Nesta esteira, citar um desempenho de Michael Jackson ou mobilizar uma imagem de Metropolis de Fritz Lang não altera, no entendimento de Gunthert (2016), a abordagem que olha o ato icónico como um ato de arte. Embora consideremos que importaria mobilizar outros olhares para a discussão sobre o ato icónico, facilmente se compreende que a arte, sendo o campo onde o autor se move, constitua o eixo central da sua análise. Para além disso, recentemente, o autor salienta que para compreendermos as problemáticas atuais é essencial incluir o mundo dos artefactos na definição de pensamento ativo e de ação pensante das pessoas (Bredekamp, 2016).

A questão que se nos coloca pela leitura desta obra prende-se com o carácter aparentemente determinista que se associa às imagens e ao seu poder destrutivo, em particular no caso do ato icónico substitutivo. A análise do autor é fundamentada em acontecimentos concretos, em imagens que percorreram o mundo digital e que entraram na casa e nas mentes das pessoas. Importa discutir se não terá a educação crítica e reflexiva 
em torno das imagens um papel decisivo na construção de cidadãos que questionam, que desconstroem, que se distanciam da imagem para melhor a compreender e interrogar. Estudos desenvolvidos a propósito do modo como os jovens reconstroem imagens em movimento (Macedo, 2016) indicam que quando há uma reflexão e se discute os significados das imagens, há a potencialidade de reconstrução de visões sobre os outros, sobre o mundo e sobre as próprias imagens. Este exercício do olhar crítico sobre as imagens poderá constituir um meio para combater o poder destrutivo do ato icónico substitutivo, para a mudança social e para a paz.

\section{REFERÊNCIAS BIBLIOGRÁFICAS}

Austin, J. L. (1962). How to do things with words. Boston: Harvard University Press.

Bredekamp, H. (2016, 11 de novembro). Réflexions sur le phénomène d'acte d'image. [Blogue] Huffpost. Retirado de http://www.huffingtonpost.fr/horst-bredekamp/reflexions-sur-le-phenomene-dactedimage_b_8555794.html

Gombrich, E. (1996). L' Art et l'Illusion. Psychologie de la représentation picturale. Paris: Gallimard.

Gunthert, A. (2016, 3 de fevereiro). L'acte d'image, un acte manqué? [Blogue] L'image sociale. Le carnet de recherches d'André Gunthert. Retirado de http://imagesociale.fr/2767

Macedo, I. (2016). Os jovens e o cinema português: a descolonização do imaginário? Comunicação e Sociedade, 29, 291-309. Retirado de http://revistacomsoc.pt/index.php/comsoc/article/view/2421

Searle, J. R. (1969). Speech acts: an essay in the philosophy of language. Londres: Cambridge University Press.

\section{NotA BIOGRÁFICA}

Isabel Macedo é doutorada em Estudos Culturais, especialidade de Comunicação e Cultura pela Universidade do Minho. Os seus principais interesses de investigação conjugam as áreas da memória cultural, da identidade social, da cultura visual, do cinema e das relações interculturais. Publicou vários artigos em revistas nacionais e internacionais: "Diasporic Identity(ies) and the Meaning of Home in Autobiographical Documentary Films"; "Audiovisual Post-colonial Narratives: Dealing with the Past in Dundo, Colonial"; "(Post)-conflict Memories and Identity Narratives in the Documentary Series 'I Am África'”.

E-mail: isabelmaced@gmail.com

Centro de Estudos de Comunicação e Sociedade, Instituto de Ciências Sociais, Campus de Gualtar, 4710-057 Braga, Portugal

*Submetido: 15/03/2017

* Aceite: 10/05/2017 